\title{
Urinary tract dysfunction in multiple sclerosis: is there a relation with disease-related parameters?
}

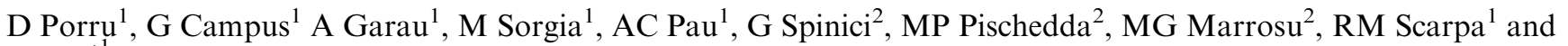 \\ E Usai ${ }^{1}$ \\ ${ }^{1}$ Clinica Urologica, Università di Cagliari; ${ }^{2}$ Istituto di Neuropsichiatria Infantile Università di Cagliari e Centro \\ Regionale di diagnosi e cura Sclerosi Mutipla, Cagliari, Italia
}

\begin{abstract}
The lower urinary tract is affected by multiple sclerosis in many patients. We screened urologically and neurologically 120 patients with a confirmed diagnosis of multiple sclerosis. The mean age was 42 years (range 22 to 69 years). Urodynamic investigation as well as neuro-urophysiological investigations were performed in all patients. Renal ultrasound was used to study morphology, and excretory urogram (IVU) was used to assess renal function and the upper urinary tracts in 105 patients. Obstructive symptoms were found more commonly than irritative symptoms. The urinary symptoms were found to be related to disease duration and not to disability status. Urodynamic abnormalities were statistically significantly related to disease duration $\left(\mathrm{X}_{2}=38.51\right.$; $P=0.0001)$, and to the disability status $\left(\mathrm{X}_{2}=76.70 ; P=0.0001\right)$. Few patients, only $3.3 \%$, had upper urinary tract dilatation. With medical management, hydronephrosis disappeared in all of the patients and did not recur. A combination of oral pharmacological agents and clean intermittent catheterization was used in the majority of the patients.

We conclude that lower urodynamic abnormalities can be present in every patient with multiple sclerosis, and appear to be related to disease duration and disability status, thus early treatment based upon urodynamic evaluation and close follow-up can reduce morbidity and improve the quality of life.
\end{abstract}

Keywords: neuropathic bladder; multiple sclerosis; urinary tract abnormalities

\section{Introduction}

Vesicourethral dysfunction is a common finding in patients afflicted with multiple sclerosis, the reported incidence being as high as $75 \% .^{1,2}$ Fortunately, upper tract complications and renal failure in multiple sclerosis are extremely uncommon. ${ }^{3,4}$

Some studies report that objective lower urinary tract dysfunction can be present without complaints. ${ }^{5}$ Several investigators found a poor relationship between the subjective complaints and the objective neurological parameters. Therefore, a neurourological diagnostic evaluation seems to be mandatory both in patients with urological complaints and in those without symptoms. Few authors ${ }^{6,7}$ studied the relationship between urological abnormalities and the severity and state of disability of the other features of multiple sclerosis. The aim of our study was to compare urodynamic behaviour with disease duration, physical examination, and disability status.

\section{Patients and methods}

Between January 1992 and October 1995, 120 patients with a confirmed diagnosis of multiple sclerosis were

Correspondence: Daniele Porru, Via Lunigiana, 1, 09122 Cagliari, Italy evaluated. The mean age was 42 years (range 22 to 69 years). Patient evaluation included a detailed neurourological examination including evaluation of anal sphincter tone, bulbocavernosus reflex and knee and ankle reflexes; the disability was established according to the Kurtzke expanded disability status scale. According to this scale, patients are divided into eight groups (Table 1); we grouped the patients in four classes (I-IV), including eight groups. ${ }^{1-8}$ Patient complaints were classified as irritative, obstructive and urinary incontinence. Urodynamic investigation as well as neuro-urophysiological investigations were performed in all of the patients. Renal ultrasound or excretory urogram (IVP) were used to assess renal function and the upper tracts in 105 patients. Urodynamic examination was performed according to the standards of the International Continence Society. ${ }^{9}$ The residual urine was measured by means of catheterization before and after the urodynamic investigation. During cystometry special attention was paid to the first desire to void and the maximum cystometric capacity. A first desire to void of $200 \mathrm{ml}$ or more in combination with a maximum cystometric capacity of $500 \mathrm{ml}$ or more was considered hyposensitive. On the contrary, a first desire to void of $50 \mathrm{ml}$ or less was considered hypersensitive. 
Table 1 Patient distribution

\begin{tabular}{lc}
\hline Disease duration (mos.) & No. Pts. \\
\hline 1 to 48 & 18 \\
49 to 108 & 14 \\
109 or more & 88 \\
Expanded disability status scale: & \\
1 & 12 \\
2 & 18 \\
3 & 18 \\
4 & 5 \\
5 & 7 \\
6 & 22 \\
7 & 12 \\
8 & 26 \\
Course of disease & \\
chronic-progressive & 55 \\
exacerbating-remitting & 65 \\
\hline
\end{tabular}

The course of the disease was documented in each patient as being exacerbating-remitting and/or chronic-progressive. The intracranial and spinal lesions, documented by means of magnetic resonance imaging (MRI), were evaluated in 105 patients.

For the statistical comparison of two-sample distributions of an (at least) ordinal variable, the Wilcoxon two-sample test was appropriate. If the $P$ value of the statistical test was $<0.05$ the difference between the two samples was considered statistically significant.

\section{Results}

Gender differences among the groups regarding the following classification parameters were not statistically significant. The group distributions regarding multiple sclerosis classification parameters of disease duration and disability status are given in Table 1. Lower urinary tract symptoms were present in all of the patients. Obstructive complaints were found more frequently than irritative complaints in the early (1-48 months) and in late stages $(>109$ months) of the disease. Table 2 shows that disease duration is related to the clinical symptoms. It also shows that urinary tract symptoms are not related to the disability status score. Urodynamic abnormalities were statistically significantly related to disease duration $\left(\mathrm{X}_{2}=38.51 ; P=0.0001\right)$ (Table 3$)$. Urodynamic abnormalities were also related to the disability status scale (Table 4). Gender differences among the groups regarding the aforementioned parameters were not statistically significant. On MRI examination 96 patients out of 105 had intracranial or spinal lesions of various grade. The imaging of the upper tracts showed dilatation in only four patients $(3.3 \%)$. With medical management, hydronephrosis improved and then disappeared in all of the patients and did not recur. In
Table 2 Urological symptoms in relation to disease duration and disability status score

\begin{tabular}{|c|c|c|c|}
\hline \multirow[b]{2}{*}{$\begin{array}{l}\text { Disease } \\
\text { duration }\end{array}$} & \multicolumn{3}{|c|}{ Urological symptoms } \\
\hline & Irritative & Obstructive & Incontinence \\
\hline (mos.): $1-48$ & 11 & 31 & 13 \\
\hline $49-108$ & 15 & 11 & 7 \\
\hline$>109$ & 17 & 41 & 39 \\
\hline \multirow{2}{*}{\multicolumn{3}{|c|}{ Disease duration: $1-48$ versus $49-108$}} & $=0.052$ \\
\hline & & $>109$ & $=0.014$ \\
\hline & $49-108 v$ & us $>109$ & $=0.091$ \\
\hline \multicolumn{4}{|c|}{ Expanded disability status score: } \\
\hline 1 & 4 & 10 & 1 \\
\hline 2 & 4 & 14 & 10 \\
\hline 3 & 8 & 18 & 10 \\
\hline 4 & 4 & 2 & 2 \\
\hline 5 & 4 & 4 & 2 \\
\hline 6 & 10 & 20 & 14 \\
\hline 7 & 8 & 8 & 10 \\
\hline 8 & 4 & 20 & 16 \\
\hline$P$ Value & $X_{2}=4.775$ & $P=0.57$ & \\
\hline
\end{tabular}

Table 3 Urodynamic findings in relation to disease duration

\begin{tabular}{lccc}
\hline $\begin{array}{l}\text { Urodynamic } \\
\text { findings }\end{array}$ & \multicolumn{3}{c}{ Disease duration } \\
\hline Dyssynergia & $1-48$ & $49-108$ & $>109$ \\
Hypersensibility & 13 & 15 & 48 \\
Hyposensibility & 13 & 2 & 5 \\
Hyperactivity & 16 & 11 & 16 \\
Hypoactivity & 16 & 2 & 34 \\
Hyperactivity & 7 & 13 & 28 \\
$\quad$ + hypoactivity & & 2 & 20 \\
\hline
\end{tabular}

$\mathrm{X}_{2}=38.51 \quad P=0.0001 ;$ Disease duration: $1-48$ vs. $49-108$ $P=0.003 ; \quad 1-48$ vs. $>109 P=0.0009 ; 49-108$ vs. $>109$ $P=0.005$

most patients with a severe disability status score a chronic-progressive course of the disease was observed, while a exacerbating-remitting course was more common in patients with a less severe disability status.

With regard to treatment, which was based upon the different urodynamic findings, the interval to follow-up was influenced by the severity of the urodynamic findings. Most patients, 77, were treated with a combination of oral pharmacological agents and clean intermittent catheterization. Behavioural modification, performed on eight patients, included timed voiding and fluid restriction. In six patients with voiding symptoms refractory to oral pharmacological drugs, or with intolerable systemic side effects, intravesical oxybutynin was used $(5 \mathrm{mg}$ oxybutynin tablet dissolved in $30 \mathrm{cc}$. saline, instilled for 45 minutes by catheter). Six patients reported significant improvement in the voiding symptoms. 
Table 4 Urodynamic findings in relation to disability status scale

\begin{tabular}{|c|c|c|c|c|c|c|c|c|}
\hline \multirow{3}{*}{$\begin{array}{l}\text { Urodynamic } \\
\text { findings }\end{array}$} & \multicolumn{8}{|c|}{ Disability status scale } \\
\hline & \multicolumn{2}{|c|}{$I$} & \multicolumn{2}{|c|}{$I I$} & \multicolumn{2}{|c|}{ III } & \multicolumn{2}{|c|}{$I V$} \\
\hline & 1 & 2 & 3 & 4 & 5 & 6 & 7 & 8 \\
\hline Dyssynergia & 3 & 7 & 9 & 2 & 2 & 17 & 1 & 17 \\
\hline Hypersensibility & 2 & 1 & 3 & 1 & 1 & 1 & 1 & 1 \\
\hline Hyposensibility & 3 & 7 & 5 & 1 & 1 & 11 & 5 & 15 \\
\hline Hyperactivity & 1 & 7 & 11 & 2 & 2 & 11 & 5 & 9 \\
\hline Hypoactivity & 11 & 9 & 9 & 3 & 1 & 13 & 7 & 5 \\
\hline
\end{tabular}

$\mathrm{X}_{2}=76.70 P=0.0001$; Disability scale: I vs. II $\mathrm{X}_{2}=15.66 P=0.02$; I vs. III $\mathrm{X}_{2}=30.73 P=0.0001 ;$ I vs. IV $\mathrm{X}_{2}=59.36 P=0.0001$; II vs. III $\mathrm{X}_{2}=7.009 P=0.42$; II vs. IV $\mathrm{X}_{2}=25.81 P=0.0005$; III vs. IV $\mathrm{X}_{2}=13.10 P=0.06$

\section{Discussion}

The hallmark of multiple sclerosis is a changing neurological behaviour with varying clinical symptoms, usually in a stepwise progression. ${ }^{10}$

Disturbances in micturition as well as sexual function are important features of the neurological disorder in patients with multiple sclerosis. In general, the severity of the bladder symptoms parallels the severity of the neurological symptoms, particularly those involving the corticospinal tracts. The aim of therapy is to protect and preserve renal function, and eradicate symptomatic voiding dysfunction and incontinence to provide a normal life-style. In most studies, irritative bladder symptoms were seen more frequently than obstructive symptoms $(60 \%$ versus $25-33 \%) .^{11-13}$ We found that obstructive symptoms were more prevalent.

Some authors ${ }^{14}$ have already reported that multiple sclerosis patients with a short disease duration can suffer from serious voiding problems, but usually micturition problems appear related to the disability status. $^{7,11,14}$

Our findings confirm a statistically significant positive relationship between disease duration and micturition complaints ${ }^{7}$ (Table 2). On the other hand, we did not find a significant relation between lower urinary tract symptoms and the disability status, when considering four classes of patients, each including two groups, according to the Kurtzke disability status scale (Table 2). Urodynamic abnormalities were significantly related to both disease duration and the disability status (Tables 3-4). An important finding of some studies 5 is the sizable percentage of urodynamic abnormalities in urologically silent multiple sclerosis patients. Half of the patients who did not have urinary complaints on questioning had objective urodynamic abnormalities. ${ }^{5}$ This confirms once more that lower urinary tract symptoms do not correlate with the underlying pathophysiology of bladder dysfunction, and suggests that urodynamic evaluation is necessary. Some authors ${ }^{15}$ suggest that the urological evaluation of this disease should be limited to physical examination and post-void residual urine measurement; we agree with other investigators ${ }^{10,16}$ that urodynamic evaluation of bladder function is critical to establish a treatment program.

Drug treatment may require adjustment to find an effective agent, without serious side effects. Intravesical oxybutynin proved to be effective in six out of eight patients $(75 \%)$, and systemic side effects were absent.

Detrusor hypoactivity was the prevalent urodynamic abnormality we observed, followed by detrusor hyperactivity; a combination of both findings was noted in almost a quarter of all patients. This explains why clean intermittent catheterization, usually in combination with oral or intravesical anticholinergic drugs, was the most common treatment adopted.

In our study only four patients $(3.3 \%)$ had upper urinary tract dilatation. The incidence in the literature is low in multiple sclerosis patients compared to the spinal cord injury patient population. Blaivas and Barbalias ${ }^{17}$ identified certain risk factors referable to voiding dysfunction in patients with multiple sclerosis. These include an indwelling catheter, detrusor striated sphincter dyssynergia in men and decreased compliance, resulting in sustained intravesical pressures greater than $40 \mathrm{~cm}$ of water.

We found that multiple sclerosis patients who are clinically stable after an initial complete evaluation usually do not require annual evaluation of the upper tract.

\section{Conclusions}

Namerow and Thompson ${ }^{18}$ described the current state of knowledge succinctly when they said: 'One should be clear in differentiating the disease process per se from the causes of symptoms, since the two may at times be quite independent'.

Urologists should realize that each patient with multiple sclerosis can suffer from lower urinary tract disorders, not necessarily related to the duration of the disease or to the disability status. The goal of management of these patients is to preserve renal function, and to control their most bothersome 
urinary symptoms. Urodynamic abnormalities appear to be related to disease duration and disability status, thus we think that early treatment based upon objective criteria, urodynamic evaluation and closer follow-up can reduce morbidity and improve quality of life.

\section{References}

1 Brickner RM. Sensory and other aspects of multiple sclerosis Bull Neurol Inst New York 1936; 5: 16-20.

2 Van Poppel H, Vereecken RL, Leruitte A. Neuromuscular dysfunction of the lower urinary tract in multiple sclerosis. Paraplegia 1983; 21: $374-379$.

3 Bradley WE. Urinary bladder dysfunction in multiple sclerosis. Neurology 1978; 28: $52-58$.

4 Chancellor MB, Kaplan SA, Blaivas JG. Detrusor externalsphincter dyssinergia. In: Chancellor MB, Kaplan SA, Blaivas JG (ed). 'Neurobiology of incontinence' CIBA foundation symposium 151, Chichester, John Wiley, 1990, pp 195-213.

5 Bemelmans BLH et al. Evidence for early lower urinary tract dysfunction in clinically silent multiple sclerosis. J Urol 1991; 145: $1219-1224$.

6 Goldstein I, Siroky MB, Sax DS, Krane RJ. Neurourologic abnormalities in multiple sclerosis. J Urol 1982; 128: $541-545$.

7 Awad SA et al. Relationship between neurological and urological status in patients with multiple sclerosis. J Urol 1984; 321: $499-$ 503.

8 Kurtzke JF. Rating neurologic impairment in multiple sclerosis: an expanded disability status scale (EDSS). Neurology 1983; 33: $1444-1449$.
9 Abrams P, Blaivas JG, Stanton SL, Andersen JT. Standardisation of terminology of lower urinary tract function. Neurourol Urodynam 1988; 7: 403 - 407.

10 McGuire EJ, Savastano JA. Urodynamic findings and long-term outcome management of patients with multiple sclerosis-induced lower urinary tract dysfunction. J Urol 1984; 132: 713-716.

11 Miller H, Simpson CA, Yeates WK. Bladder dysfunction in multiple sclerosis. Br Med J 1965; 1: 1265-1268.

12 Bradley WE, Logothetis JL, Timm GW. Cystometric and sphincter abnormalities in multiple sclerosis. Neurology 1973; 23: 1131 .

13 Andersen JT, Bradley WE. Abnormalities of detrusor and sphincter function in multiple sclerosis. Br J Urol 1976; 48: $193-196$.

14 Koldewijn EL et al. Relationship between lower urinary tract abnormalities and disease-related parameters in multiple sclerosis. J Urol 1995; 154: 169-173.

15 Kornhuber HH, Schulz A. Efficient treatment of neurogenic bladder disorders in multiple sclerosis with initial intermittent catheterization and ultrasound-controlled training. Eur Urol 1990; 30: $260-264$.

16 Gonor SE, Carroll DJ, Metcalf JB. Vesical dysfunction in multiple sclerosis. Urology 1985; 25: 429-432.

17 Blaivas JG, Barbalias GA. Detrusor external sphincter dyssynergia in men with multiple sclerosis: An ominous urologic condition. J Urol 1984; 131: $94-98$.

18 Namerow NS, Thompson LR. Plaques, symptoms and the remitting course of multiple sclerosis. Neurology 1969; 19: $765-774$. 